\title{
The virus crisis affects Orthopaedic surgery and scientific activities worldwide
}

\author{
Andreas F. Mavrogenis ${ }^{1} \cdot$ Andrew Quaile $^{2}$ - Marius M. Scarlat ${ }^{3}$
}

Published online: 11 April 2020

(C) SICOT aisbl 2020

There is no doubt that 2020 did not start well. At the end of December 2019, an infectious disease caused by the severe acute respiratory syndrome coronavirus 2 (SARS-CoV-2), subsequently named the coronavirus disease 2019 (COVID19) was identified in Wuhan, the capital of Hubei region, China. Since then, the disease spread globally, resulting in the 2019-2020 coronavirus pandemia (from the Greek pan"all" and dēmos "people"; meaning "pertaining to all people"). As of March 28, 2020, the pandemia led to worldwide crisis (from the Greek krisis used by Hippocrates and Galen as the "turning point of a disease when an important change takes place, indicating recovery or death"); the overall rate of deaths per number of diagnosed cases was $4.6 \%$ ranging from $0.2 \%$ to $15 \%$ according to age group and other health problems [1].

By the time of writing, Europe and North America have suffered thousands of victims. Hopefully, there are there no new reported cases in Hubei, China, and Chinese scientists are generously providing medical knowledge and equipment to other continents (Figure 1). Many Chinese researchers support the effect of traditional Chinese medicine for the present and similar viral infections [2]. They used traditional Chinese medicine remedies extracted from traditional Chinese herbs [3], similarly to the pharmacies used in the Asclepian and Hippocratic Medicine for the therapy of humans in antiquity [4].

\section{Orthopaedic surgery}

The virus has knocked thousands of health workers out of action in Europe. As doctors, nurses and other practitioners

Marius M. Scarlat

mscarlat@gmail.com

1 First Department of Orthopaedics, School of Medicine, National and Kapodistrian University of Athens, Athens, Greece

2 Spineworks, Hampshire Clinic, Basingstoke, Hampshire, UK

3 Clinique St. Michel, Groupe ELSAN, Toulon, France fall sick, the burdens increase on health care systems already groaning under the strain of the pandemia. Importantly, infected workers and their hospitals are increasingly being recognized as vectors for the spread of the virus (https://www. nytimes.com/2020/03/24/world/europe/coronavirus-europecovid-19.html). Physicians on the front line are most at risk, not simply of getting infected but of getting the infection in its most severe form. Orthopaedic surgeons are not in the frontline but definitely they are affected by this crisis. In the most affected countries, orthopaedic surgeons are urged to work outside their specific areas of training and expertise; surgeons are re-trained and transferred to primary and emergency care units to help in overwhelmed specialties. Outpatient clinics are shut down, elective operations are cancelled, and non-urgent operations are suspended for at least three months from now. The operating theatres are transformed into intensive care units (ICU) and reserved for ventilation and respiratory management of these patients. Surgical operations being performed now are the most desperate cases that cannot wait. Surgery is reserved for trauma and life-threatening conditions such as cancer or severe infections (https://www. sciencesetavenir.fr/sante/coronavirus-covid-19-plan-blancmaximal-et-cheque-en-blanc-pour-1-hopital_142437).

Dealing with orthopaedic trauma is facing many difficulties as the medical system is reserved for symptomatic and medically ill COVID-19 patients. Despite services and traffic lockdown, motor vehicle accidents do still occur. Additionally, elderly people keep falling because the risk of falls in this population is a crisis that will never end. Many trauma patients in the present pandemia are also potential or confirmed COVID-19 patients; this makes the treating orthopaedic surgeons the front-line treating physicians. Both these groups of patients are managed as soon as possible by the orthopaedic teams on duty, and are discharged home in a fast track method. However, often, the indications for conservative treatment are extended to include entities that traditionally were treated operatively. NSAIDs prescribed for a variety of inflammatory conditions are nowadays less frequently used 
Fig. 1 Photograph of the front cover of the Handbook of COVID-19 prevention and Treatment published by a group of medical experts from the frontlines of the pandemia in China

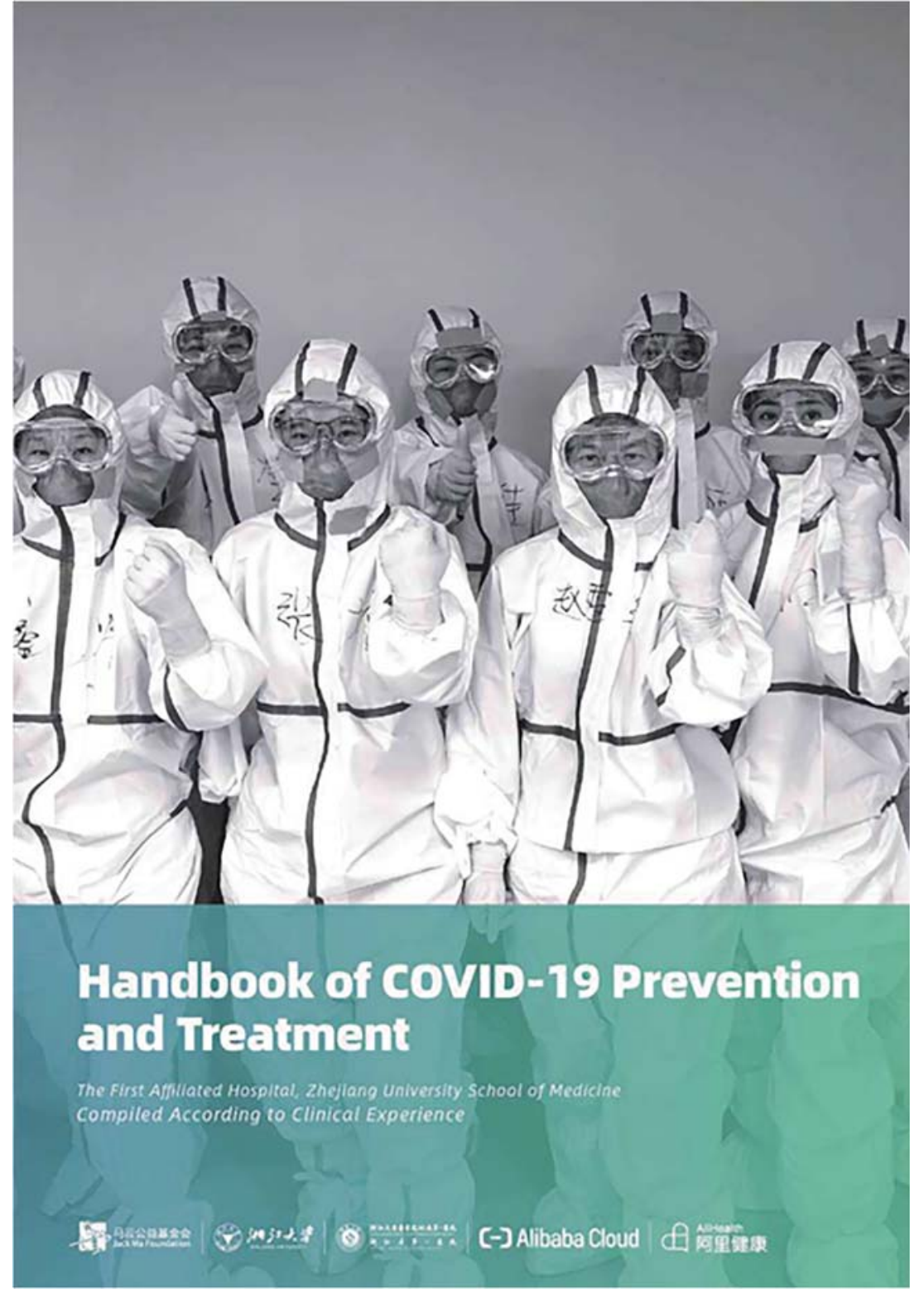

because of the recommendations of caution for the management of COVID-19 symptoms. There is speculation regarding the potential mechanisms ranging from dampening of the immune system to altered fluid shifts exacerbating pneumonia [5]. Some organisations have published advice on the use of steroids for non-operative pain control due to concerns over the potential for immunosuppression [6].

Hopefully, orthopaedic associations have published and continuously update their information for their members on trauma and orthopaedic care during COVID-19 pandemia (https://www.boa.ac.uk/resources/covid-19-boasts-combined. html, https://www.england.nhs.uk/coronavirus/wp-content/ uploads/sites/52/2020/03/specialty-guide-orthopaedictrauma-and-coronavirus-v1-16-march-2020.pdf). This information is aimed at non-elective patients, who are predominantly trauma-related, that cannot be postponed and will continue to need care. It classifies patients into four categories including obligatory in-patients, eg., hip fracture patients, that should avoid pre-operation delay and expedite rehabilitation to minimise length of stay; non-operative patients, eg., injuries that can reasonably be managed either operatively or non-operatively, non-operative care should be explored first, especially if this avoids admission; day-cases, for which surgery can be safely undertaken for a large number of conditions; and first contact and clinics, which should be kept to the safe minimum (https://www.england.nhs.uk/coronavirus/wpcontent/uploads/sites/52/2020/03/specialty-guideorthopaedic-trauma-and-coronavirus-v1-16-march-2020.pdf). Telemedicine is used in some countries, however, although it might work for a tendinitis or carpal tunnel syndrome, it 
cannot be useful if the patient experiences a fracture. It is though, a useful technique for offering advice on pain control and rehabilitation.

Most surgeons avoid operating at this stage. This is due to the dangers of poor protection and testing including the inability of routine checks on patients, lack of personal protective equipment, poor subsequent psychology for the risk of getting infected, and increased stress of going to the emergency room for non-urgent things. These factors increase the risk of contamination of the medical team. (https://www.bloomberg. com/opinion/articles/2020-03-24/the-coronavirus-crisis-isputting-surgeons-at-risk-too). Operating rooms are sterilized environments, but that does not guarantee protection against COVID-19. Aerosols can leave the virus everywhere on plastic, metal and cardboard, and it can remain there for several hours or few days. The combination of power surgical tools and ventilation systems can produce a viral wind into the operating room. These may turn the operating rooms into viral labs with strong casualties amongst the operating room and surgical personnel (https://www. bloomberg.com/opinion/articles/2020-03-24/the-coronaviruscrisis-is-putting-surgeons-at-risk-too). Standard surgical face masks do not provide sufficient protection. As a result of the pandemia, we learned about the FFP2 and FFP3 face masks, however, these are not available for all, and the low quantity available is reserved only for front-line infectious diseases specialists that admit febrile patients with possible COVID19. Blood products are not a favoured route of infection, but blood donors are now screened for the virus (https://www. bloomberg.com/opinion/articles/2020-03-24/the-coronaviruscrisis-is-putting-surgeons-at-risk-too).

To the best of our knowledge, at this stage there is no unified hospital protocol for managing the COVID-19 patients within surgical settings, except that the standard surgical face mask and the usual scrubs. Ideally, the heavy-duty protection China put in place should be mimicked as well, and hospitals should be testing medical staff daily so that their COVID-19 status is clear and those who are transmitters can be isolated (https:// www.bloomberg.com/opinion/articles/2020-03-24/thecoronavirus-crisis-is-putting-surgeons-at-risk-too). However, the availability of tests is still limited, and many are false negative. Therefore, no one really knows the infection rate in surgical settings. Also if they get to know, many doctors and nurses will have to leave hospitals and be quarantined at home, which would cause the health system to collapse (https://www. bloomberg.com/opinion/articles/2020-03-24/the-coronaviruscrisis-is-putting-surgeons-at-risk-too).

It is our belief that the pandemia will result in an enormous burden for countries with increased related mortality and morbidity that will be very difficult to be addressed by the existing health systems. Therefore, the delivery of services for the patients with musculoskeletal injuries must be strengthened, and the capacity to deliver services and the quality of those services must be enhanced. Worldwide surveillance and ongoing benchmarking of the surgical burden are essential to monitor the population health benefits gained with improvements in surgical services. The World Healh Organisation (WHO) and the global surgical community should develop tools and

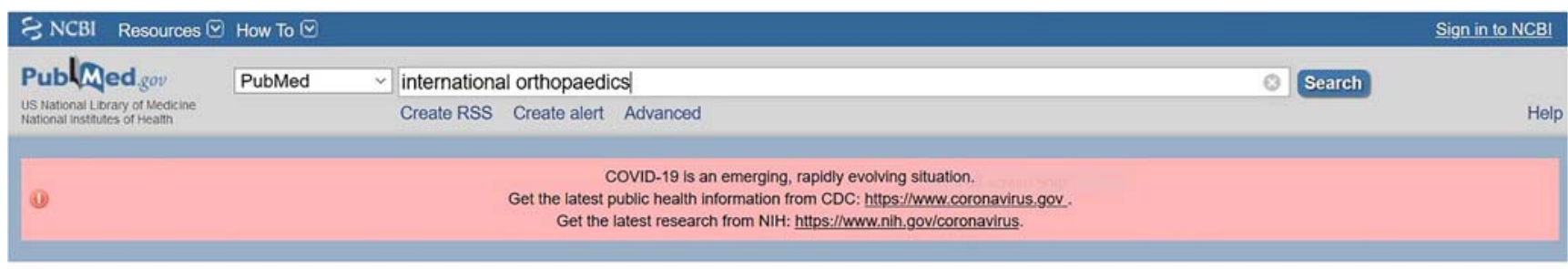

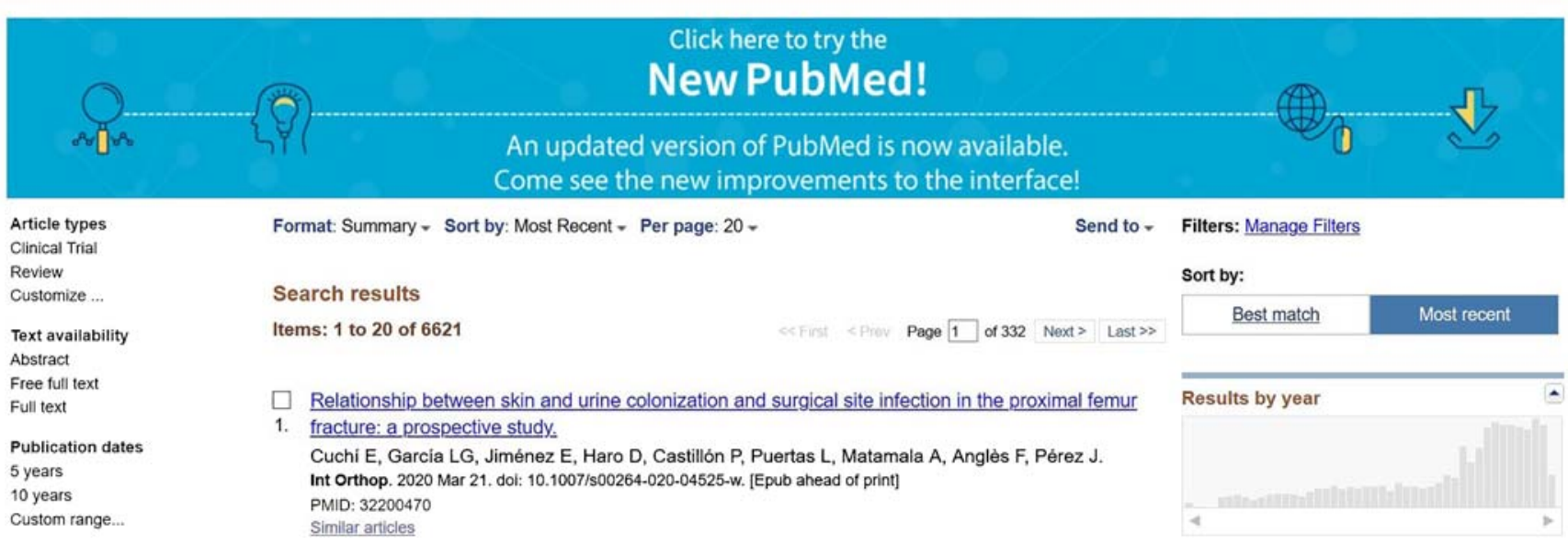

Fig. 2 Red warning sign at the webpage of PubMed suggesting increased awareness, and providing health information and up-to-date medical research 
protocols to help evaluate the surgical capacities of hospitals and assist in the management of trauma patients in crisis. The fundamental premise is that healthcare is a right, not a privilege; however, this goal often is unattainable everywhere due to economic constraints [7].

\section{Orthopaedic science}

Orthopaedic surgeons have the opportunity to work with sponsors to produce meaningful research, to define essential interventions, and to design and implement strategies to overcome barriers to the delivery of services for the injured in the event of crisis. Although there is concern about methodological issues with data collection on surgical conditions in pandemia and crisis, self-sustaining trauma registries in this area are necessary $[7,8]$. Due to the present coronavirus pandemia, a large number of Orthopaedic studies have been paused; they will probably resume as soon as the crisis hopefully fades. Many international and national meetings, congresses and courses have been cancelled, or rescheduled. At the moment of this writing, all meetings initially scheduled for the first semester of 2020 have been delayed until October to December of the current year and we are not sure how many Orthopaedic surgeons will eventually attend these meetings.

The virus spread and impact is following different patterns in different geographic areas. Northern Europe seems to have less causalities for now as the South but this could change in time. Southern China and South-Est Asia have lower numbers of cases than some regions from the North. South America or Russia have lower and different patterns of epidemics than the North America or Southern Europe, however, these are features are carefully monitored by the epidemiologists. The fact is that while some areas still seem to function "normally" others are confined and isolated with difficulties in providing medical service, including traumatology and orthopaedics.

In the near future we shall have the opportunity to evaluate international, national, regional and individual hospitals registries and response to the emergency. Many lessons will be learned and we hope the outcome will be a better coordinated response. We live in a digital age and therefore transmission of information should be possible and rapid. The military have expertise in triage and managing mass casualty situations. We should be drawing on their expertise and ability to train for and practice for such scenarios. Many countries are putting these plans into place and amongst those with such expertise are Orthopaedic and Trauma surgeons.

Medical education and writing should be continued, and should not be frightened of the crisis (Figure 2); it is a responsibility of a medical doctor to provide medical information and transfer knowledge despite casualties [9].
Over the last weeks, we appreciated an unprecedented rise of submissions to International Orthopaedics. Most likely, restriction of circulation and services lockdown has led many surgeons staying more at home to write and to finalize scientific work, and to submit their papers that were pending for long. This is interesting material that we, as editors, acknowledge and review carefully. We are however very vigilant to the quality of submissions as many old studies (sometimes over 10 years old research) that were not published or rejected, are finally submitted to find an eventual place for publication. We try to identify and warn the authors for this type of behaviour. Finding good reviewers in crisis is not easy, but it turned out to be less difficult compared to other occasions such as summer holidays; we were pleased to see that the journal's reviewers reply promptly and accept a review assignment, and return on time with a good and constructive review $[10,11]$. The editors and reviewers of the journal opt for quality publications to increase the impact of the journal and the visibility of the submitted/ published papers [12]. Because we acknowledge the effort and amount of time that are required to perform a study and to prepare and submit a manuscript, our review process aims to improve and to accept an article. However, the workflow in these weeks seems to be slower because of the high number of submissions. As Editors, we support continuous orthopaedic education, looking forward to better quality submissions and publications in "International Orthopaedics".

\section{References}

1. Coronavirus (COVID-19) Mortality Rate. Available at: www. worldometers.info. 5 March 2020. Accessed on: March 29, 2020.

2. Xu XW, Wu XX, Jiang XG, Xu KJ, Ying LJ, Ma CL, Li SB, Wang HY, Zhang S, Gao HN, Sheng JF, Cai HL, Qiu YQ, Li LJ (2020) Clinical findings in a group of patients infected with the 2019 novel coronavirus (SARS-Cov-2) outside of Wuhan, China: retrospective case series. BMJ. 368:m606

3. Yang Y (2020) Rapid response to: Clinical findings in a group of patients infected with the 2019 novel coronavirus (SARS-Cov-2) outside of Wuhan, China: retrospective case series. BMJ. 368:m606 Available at: https://www.bmj.com/content/368/bmj.m606/rr-13

4. Mavrogenis AF, Saranteas T, Markatos K, Kotsiou A, Tesseromatis C (2019) Pharmacies for pain and trauma in ancient Greece. Int Orthop. 43(6):1529-1536

5. Day M (2020 Mar 17) Covid-19: ibuprofen should not be used for managing symptoms, say doctors and scientists. BMJ. 368:m1086

6. Steroid Injections and NSAIDs COVID 19. British Association of Spine Surgeons (BASS) communication. 19.03.2020.

7. Spiegel DA, Gosselin RA, Coughlin RR, Kushner AL, Bickler SB (2008) Topics in global public health. Clin Orthop Relat Res. 466(10):2377-2384

8. Scarlat MM (2019) About Orthopaedic awards, drains, patients safety and outcomes. Int Orthop. 43(9):2001-2002 
9. Scarlat MM, Quaile A, Waddell JP (2020) Conflicts, military medicine and war casualties in international Orthopaedics. Int Orthop. 44(1):1-2

10. Mavrogenis AF, Quaile A, Scarlat MM (2020) The good, the bad and the rude peer-review. Int Orthop. 44(3):413-415

11. Mavrogenis AF, Sun J, Quaile A, Scarlat MM (2019) How to evaluate reviewers - the international orthopedics reviewers score (INOR-RS). Int Orthop. 43(8):1773-1777
12. Scarlat MM (2018) Quality of publications in "International Orthopaedics" and projects for the near future. Int Orthop. 42(12): 2735-2736

Publisher's note Springer Nature remains neutral with regard to jurisdictional claims in published maps and institutional affiliations. 